\title{
To discriminate or not to discriminate? Personalised pricing in online markets as exploitative abuse of dominance
}

\author{
Marco Botta ${ }^{1} \cdot$ Klaus Wiedemann $^{1}$
}

Published online: 9 December 2019

(c) The Author(s) 2019

\begin{abstract}
The advent of big data analytics has favoured the emergence of forms of price discrimination based on consumers' profiles and their online behaviour (i.e. personalised pricing). The paper analyses this practice as a possible exploitative abuse by dominant online platforms. The paper argues that, in view of its "mixed" effect on consumers' welfare, personalised pricing requires a case-by-case assessment under EU competition law and thus it should not be banned a priori. However, in view of the recent case law of the European Court of Justice on price discrimination, the National Competition Authorities (NCAs) and the European Commission would face a high burden of proof to sanction this conduct under Art. 102(c) TFEU. Finally, the paper argues that, due to its case-by-case approach, competition law seems more suitable than omnibus regulation to tackle the negative effects that personalised pricing could have on consumers' welfare. In particular, an NCA/the European Commission could negotiate with online platforms different kinds of behavioural commitments: transparency requirements, limits on data collection/user profiling, rights to opt out of personalised pricing and the obligation to share customers' data with competitors could significantly tame the risks of personalised pricing.
\end{abstract}

Keywords Price discrimination · Personalised pricing · EU competition law · Exploitative abuse $\cdot$ Remedies

JEL Classification $\mathrm{K} 21 \cdot \mathrm{L} 11 \cdot \mathrm{L} 41 \cdot \mathrm{L} 42 \cdot \mathrm{L} 86$

Marco Botta

marco.botta@ip.mpg.de

Klaus Wiedemann

klaus.wiedemann@ip.mpg.de

1 Max Planck Institute for Innovation and Competition, Munich, Germany 


\section{Introduction}

The past decade has witnessed the rapid proliferation of new business models that mainly rely on the processing of large amounts of users' data, commonly known as "big data". Besides traditional personal data, such as gender, age and level of education, other information is essential for online platforms. In particular, past online purchases, geo-location, the list of web sites previously visited, as well as search queries are part of the data daily collected by online platforms. Such information is collected either directly from the users (i.e. when the latter log into the platform), or via cookies or purchased from data traders (Miller 2014, 43).

Nowadays, algorithms can process millions of pieces of data, building personal profiles of individual consumers (OECD 2015, 26). In particular, via data mining, online platforms can "connect" different pieces of information in order to elaborate as detailed users' profiles as possible and thus predict the consumers online behaviour. The platform can use this knowledge either to advertise a specific product to the consumer (i.e. targeting advertising), or to adjust the price to demand fluctuations in real-time (i.e. dynamic pricing) (Miller 2014, 46). Finally, the platform can rely on the collected data to persuade the consumer to buy a certain product by offering a special discount or purchase conditions (e.g. exemption from the payment of the delivery costs of the product); a "special" price not necessarily offered to other customers. "Personalised pricing" is, therefore, a logical consequence of the large amount of personal data collected by online retailers and of the new possibilities algorithms and data mining offer (Shiller 2014).

While personalised pricing is considered a new business practice in digital markets, this conduct brings up a number of questions under EU competition law. In particular, Art. 102(c) of the Treaty on the Functioning of the European Union (TFEU) sanctions dominant companies which "apply dissimilar conditions to equivalent transactions with other trading parties, thereby placing them at a competitive disadvantage". "To discriminate or not to discriminate" is thus the Hamletic dilemma that several online platforms are currently facing, divided between new business opportunities offered by big data analytics and the possible sanctions under EU competition law.

The paper discusses this dilemma by looking at three interrelated research questions: first of all, the paper analyses the impact of personalised pricing on the consumers' welfare by looking at recent economic theories in this field. Secondly, the paper discusses the enforcement challenges that a National Competition Authority (NCA)/the European Commission would face in investigating a case of personalised pricing under Art. 102(c) TFEU. In Sect. 4, the paper analyses the recent case law of the Court of Justice of the European Union (CJEU) in MEO (Case C-525/16), in order to understand the impact of this ruling on the assessment of personalised pricing under Art. 102(c) TFEU. Finally, the paper compares antitrust remedies to the solutions provided by EU data protection and consumer law to tackle the issues related to personalised pricing in digital markets. In particular, the paper discusses the hypothesis that an NCA/the European Commission might be well advised to look at data protection law principles when 
designing behavioural remedies: limits on profiling and the obligation to share customers' data with competitors, for instance, would reduce the risks involved in personalised pricing. Similarly, in line with EU consumer law acquis, transparency requirements and opt-out rights concerning personalised pricing could represent suitable remedies to limit the negative effects of personalised pricing on consumers' welfare.

Economists traditionally differentiate between forms of price discrimination that harm a rival ("primary line injury") and those that harm a direct customer of the firm ("secondary line injury"). In this paper, we look exclusively at the "exploitative" dimension of personalised pricing by dominant online retailers vis-à-vis final consumers-i.e. secondary line of injury. Finally, in this paper we only assess personalised pricing as a possible "abuse" of dominance. On the other hand, we do not look at the issue of relevant market definition, which has extensively been discussed in the literature on multi-sided markets (e.g. Graef 2015; Filistrucchi et al. 2013; Rochet and Tirole 2006). Similarly, we do not analyse the market power of online platforms, since a number of authors have already discussed whether the accumulation of large amounts of data (i.e. big data) may represent an entry barrier, and thus a source of market power for online platforms (e.g. Rubinfeld and Gal 2017; Schepp and Wambach 2016; Lianos and Motchenkova 2013).

The paper contributes to the on-going discussion about the implications of personalised pricing for competition policy (e.g. OECD 2015, 2018, White House 2015). In particular, it contributes to this debate by putting forward (in Sect. 5) a number of ideas on possible behavioural remedies that a competition agency could adopt in order to minimize the negative effects of personalised pricing. Finally, the paper is relevant in view of the provisions contained in the General Data Protection Regulation (GDPR Reg. 2016/679), applicable since 25 May 2018. This contribution thus raises a number of questions regarding the interaction of EU competition, consumer and data protection law.

\section{Price discrimination in online markets}

Since the work of Pigou (1920) in this area, economists traditionally identify "3 degrees" of price discrimination:

- First-degree price discrimination takes place when a firm is able to perfectly discriminate among its customers, adjusting the price of the product to the individual customer's willingness to pay. In this hypothetical scenario, the firm would be able to extract the maximum profit on each sale.

- Second-degree price discrimination means that the firm discriminates between its customers by granting discounts once a specific purchase quota is achieved ("non-linear pricing"). This includes two-part tariffs as well as versioning (i.e. offering the "same" product at different quality levels and prices). This conduct is usually considered pro-competitive, and it can increase the consumers' welfare. 
- Third-degree price discrimination takes place when the firm charges different prices to different groups of customers. Third-degree price discrimination is rather common in the "real" economy, and it is generally justified by fairness considerations. For example, a movie theatre grants a special tariff to certain categories of "vulnerable" consumers, such as retired people, students or children below a certain age.

Traditionally, first-degree price discrimination has been considered de facto impossible: the seller would not have enough information to accurately differentiate the price of the product or service for each customer (Geradin and Petit 2006, 485). Nevertheless, as found by a 2015 White House report, big data analytics and the increased computing power of algorithms are facilitating the shift from second/ third-degree price discrimination to first-degree price discrimination (White House Report 2015, 19). Online platforms cannot sufficiently "guess" the individual willingness to pay (yet). However, big data analytics allow online platforms to divide their customers into smaller groups than in the past. This means that it is nowadays easier to identify the expected willingness to pay for each group for a certain product - and to adjust the price accordingly (OECD 2018, 9).

While individual pricing is (still) not reality, big data analytics favour the emergence of different forms of price discrimination in digital markets (Ezrachi and Stucke 2016, 96). The latter can be described as a mix of the different degrees of price discrimination described above, combined with different forms of personalisation (Ezrachi and Stucke 2016, 107-110):

- Steering: A search engine could differentiate the list of results shown to different categories of consumers, even though the consumers submitted the same search query (this practice is also known as "search discrimination"). For instance, Google could assign a higher search ranking to "cheaper" products for consumers oriented to "budget conscious choices", in comparison to the list of products shown to "more affluent" consumers.

- Decoys: The platform could differentiate and individualise the product "decoys" presented to different categories of consumers. For instance, Apple could present a wider range of optional iPhone gadgets to "more affluent" consumers than to the "budget conscious customers" when they enter Apple's online shop, since the latter category would be unlikely to buy additional devices besides the basic model of the product.

- Drip pricing: The platform could mislead consumers by showing a low "starting price" for the product; a price to which the platform automatically adds additional charges before the purchase is finalised. The classic example in this regard are airline tickets, where the initial price is usually low to attract the attention of "budget conscious consumers", but additional charges are later added during the purchasing process (e.g. airport taxes, fuel charges, check-in luggage etc.).

- Re-offers: The platform could exploit the time constraints and test the willpower of different consumers in order to personalise their treatment. For instance, after having searched for a type of product on either Amazon or eBay without having concluded the purchase, the platform could contact the potential customer 
by re-offering that product at a discounted rate. Consequently, "more patient" consumers usually get better deals when they shop online, in comparison to "less patient" consumers who purchase a product as soon as they find what they are looking for.

- Fake special offers: The platform could frame special "fake" offers for certain categories of consumers. For instance, coming back to the last example, Amazon or eBay could mention that the special offer is individualised and is available for a limited period of time only, while in reality the "special" offer corresponds to the uniform price charged by the platform for the product. Within this scenario, less sophisticated consumers would be more likely to fall into this "trap" and accept the "special" offer of the platform.

As recently noted by the OECD, while forms of price discrimination in online markets are possible in theory, "...the extent to which personalised pricing is generally happening in real markets still remains largely unknown” (OECD 2018, 5). In particular, cases of price discrimination implemented by Amazon and Uber have been anecdotal (OECD 2018, 16-17). The platforms have promptly returned to uniform price schemes after having been criticised by consumer groups. Secondly, a number of empirical studies have tried to quantify the extent of personalised pricing in digital markets. For example, Mikians et al. have concluded that "steering" is a common form of price discrimination in online markets (2012). In their empirical study, the authors relied on a number of proxy servers that simulated search queries originating from different countries in Europe, Asia and the USA. The computers generated synchronised search queries, searching for the same product on Amazon and similar marketplaces. The authors concluded that a number of marketplaces generally "steered" users to different products, although the search query was identical, and the search was taking place at the same time on the same web site (Mikians et al. 2012, 1). In particular, users were "steered" to products dedicated to either "more affluent" or "budget conscious" customers. According to the authors, the discriminatory factors followed by the algorithms were related to the geographic origin of the search query, as well as to the amount of personal information known about the user, such as the list of web sites previously visited and the individual purchasing history. Interestingly, the operating system used did not have an impact on the search results. In other words, Mac users were not treated by the platforms as "more affluent" consumers and thus were not discriminated in comparison to Windows users (Mikians et al. 2012, 2).

The work by Mikians et al. highlights the limits of such empirical studies. In particular, the authors had to set up a large empirical study, automatically implemented by machines. However, the study was limited to a specific type of price discrimination, namely "steering". Secondly, the findings of the study on the lack of discrimination between Mac and Windows users contradict other studies in this field (for example, Hannak 2014). The results of this kind of study are strongly influenced by the variables taken into consideration and by the study set-up. In particular, it would be hard to prove that an online platform systematically implements personalised pricing and that there are no objective justifications to this behaviour. As further discussed in the next sections, the need to prove the systematic nature of discrimination 
and the possible objective justifications put forward by the online platforms are the main reasons why no competition authority so far has investigated this type of abuse under Art. 102 (c) TFEU.

\section{The economists' view on personalised pricing}

\subsection{Impact on consumers' welfare}

According to Varian, a firm discriminates its customers when it sells two or more similar goods at prices that are in different ratios to their marginal costs (Varian 1989, 598). Traditionally, the economics literature has recognised that a firm can implement an effective strategy of price discrimination when three cumulative conditions are fulfilled: the firm has some degree of market power; the firm can prevent arbitrage; the firm can estimate the consumer's valuation of a product and thus it can adjust the price accordingly.

It is important to note that personalised pricing can also be implemented by firms that are not monopolists in the markets (cf. Levine 2002). As argued in the previous section, via big data analytics the majority of digital platforms have nowadays the means to implement a strategy of price discrimination, although they might decide not to follow such strategy. Secondly, online platforms can prevent arbitrage by, for instance, customising products that are directly sold to final consumers (i.e. second condition fulfilled) (Ezrachi and Stucke 2016, 86-87). Via profiling, platforms can-depending on the kind of product at stake-adjust not only the price, but also the product features in relation to the specific demands of their customers. In addition, online platforms generally do not rely on intermediaries (e.g. wholesalers), who often engage in parallel trade. Finally, as argued in the previous section, online platforms can use profiling and estimate the reservation price for more consumers than in the past and adjust the price of the product accordingly (i.e. third condition is also fulfilled).

Economists have analysed the impact of personalised pricing in monopoly and in imperfect competitive markets. In the first scenario, the monopolist could charge a lower price to "budget conscious consumers" who have a lower reservation price, and who are also expected to be "poorer" in terms of personal income. Hence, price discrimination could increase product affordability for a larger number of consumers and thus facilitate welfare re-distribution among different categories of consumers (Bergemann et al. 2015). However, it is worth remembering that the objective of price discrimination is to "capture as much consumer surplus as possible", while welfare distribution is only a side effect of such strategy (Carlton and Perloff 1999, 280). As noted by Ezrachi and Stucke, via personalised pricing the platform can, in theory, set its price as close as possible to the consumers' reservation price (Ezrachi and Stucke 2016, 96). Without price discrimination, some consumers would pay a lower price for the product than their reservation price, and thus gain a benefit. In a monopoly scenario, personalised pricing thus favours welfare re-distribution among different categories of consumers, but it might also shift part of the welfare from certain groups of consumers to the firm. 
Although in a monopoly scenario consumers would not be able to switch to a different provider, they could "hide" their identity to avoid the implementation of a price discrimination strategy: by deleting cookies and their browsing history, relying on proxy servers and not sharing personal data online, consumers could reduce the ability of the monopoly platform to estimate their reservation price (Liu and Serfes 2004). In other words, the platform would not have access to key information to implement a successful strategy of price discrimination (i.e. the third condition mentioned in the previous paragraph would not be verified). Nevertheless, this strategy would have a number of limits. First of all, as noted by Acquisti and Varian, only "strategic" customers, who can estimate the value of their personal data and are more concerned by the risks of price discrimination, could hide their identity in the online world (Acquisti and Varian 2005, 367). By contrast, "myopic" consumers (i.e. digital illiterate) would be less cautious when it comes to leaving "traces" on the Internet (Acquisti and Varian 2005, 367). Secondly, Belleflamme and Vergote have demonstrated that relying on "hiding" technologies might not be necessarily beneficial for the consumers' welfare (Belleflamme and Vergote 2016, 142). As mentioned above, in fact, less affluent consumers might benefit from price discrimination even in a monopolist scenario. Since consumers do not know how they have been categorised by the platform, by relying on hiding technologies the consumers would be subject to the uniform price and thus they would run the risk of losing the benefits of "being discriminated".

The Internet exponentially increases the choice that consumers have in terms of product suppliers: an online monopolist that freely implements a strategy of personalised pricing is a highly unlikely scenario. Imperfectly competitive markets, where a number of online platforms have some degree of market power, are more common in the digital world. The impact of price discrimination in imperfect competitive markets varies on the basis of the categories of information that the competing platforms have access to, as well as the brand preferences and search costs that online consumers face. In a "best response asymmetry scenario", the online retailers sell the same type of product, but they do not know what brand their current and potential consumers value the most. In such a scenario, firms usually engage in price cuts to attract new consumers-i.e. price discrimination fosters competition and thus it is likely to enhance the overall consumers' welfare (Armstrong 2006, 19). By contrast, in a "best response symmetry scenario", where all the firms have access to the same information concerning the customers' preferences, the firms will rather charge higher prices to the customers that have higher search costs, and lower prices to strategic consumers who are more likely to switch to a different supplier (Townley et al. 2017, 50). In other words, in a best response symmetry scenario the firms engage in price discrimination in order "to safeguard their garden", rather than to increase the number of customers. However, the idea that price discrimination in the context of a best response symmetry scenario is detrimental for competition has been challenged by a number of authors (Cabral 2016; Rhee 2014; Esteves and Reggiani 2014). The latter studies have emphasised the importance of brand preferences and search costs, rather than symmetry of information, in relation to the impact of price discrimination on the degree of competition in the market and ultimately on consumers' welfare. 
The ambiguous effects of price discrimination on consumers' welfare show that there is no reason to ban a priori forms of personalised pricing in digital markets (Bourreau et al. 2017). As argued in the following sections, the case-by-case approach followed by EU competition rules might be more suitable to tackle the issues generated by personalised pricing than an omnibus regulation: only a dominant firm that has a substantial degree of market power, in fact, is subject to the constraints of Art. 102 TFEU.

\subsection{Personalised pricing and behavioural economics}

While the effect of price discrimination on consumers' welfare is ambiguous, behavioural economics provide a rather straight forward answer in relation to the consumers' attitude vis-à-vis price discrimination. A number of studies have confirmed that consumers generally dislike forms of price discrimination (Malc et al. 2016): if a consumer finds out that he or she has paid a higher price for a product than a friend or relative, then it is unlikely that he or she will buy from the same seller again (Maggiolino 2017, 12). However, it is worth noting that price discrimination is not a novelty of the digital era. Forms of third-degree price discrimination benefiting categories of vulnerable consumers have always existed, and they have generally been accepted by the "discriminated" customers. However, in such context the "discriminated" customers were aware of the reasons for the discrimination, which were considered socially acceptable. In online markets, by contrast, consumers might not be aware of the parameters taken into consideration by the algorithm to calculate the price, even though the charged price might actually maximise the consumer's welfare. This hypothesis has been confirmed by an empirical study carried out by Richards et al. (2016), where the consumers were more likely to accept forms of price discrimination if they had been involved, at least to some extent, in the mechanism of price setting. In other words, consumers seem to dislike the "secrecy" of personalised pricing, rather than rejecting price discrimination per se. The consumers' reluctance vis-à-vis price discrimination might explain why there is limited evidence at the moment about price discrimination in digital markets: as argued by Leibbrandt (2016), even though personalised pricing is technically feasible, firms often do not engage in such kind of strategy due to the risk of harming their brand reputation and losing the customers' confidence.

A number of authors has recently argued that the objectives of EU competition law should be "broadened", in order to include fairness considerations besides the consumer-welfare standard (Kalimo and Majcher 2017; Townley et al. 2017; Ezrachi 2017). From this perspective, price discrimination might be regarded as a good example of an "unfair" practice. However, what is "unfair" is subjective and thus unlikely to represent a meaningful threshold in relation to the scope of application of EU competition rules. In addition, behavioural economics show that consumers consider "unfair" the lack of transparency of personalised pricing in online markets, rather than price discrimination per se. As further discussed in Sect. 5, transparency requirements and opt-out rights might be more suitable remedies to solve the lack of 
consumer confidence in personalised pricing rather than a total ban of this business practice.

\section{Personalised pricing as abuse of dominance}

\subsection{Discrimination of consumers v. industrial customers}

A preliminary point of discussion in relation to the assessment of personalised pricing as a possible abuse of dominance concerns the scope of application of Art. 102 TFEU to market conducts that harm final consumers. Art. 102 TFEU lists a number of "abuses" by "one or more undertakings", but it does not specify the "targets" of such practices. In other words, Art. 102 TFEU does not specify whether this provision only sanctions abuses that harm industrial customers-or those harming final consumers, too.

By studying the travaux préparatoires of the Rome Treaty, Akman concluded that the initial intention of the EU founding fathers was to sanction under Article 102 TFEU primarily exploitative conducts that directly harmed final consumers (Akman 2009). Nevertheless, due to the high burden of proof and possible overlaps with sector-regulation, the European Commission has seldom investigated exploitative abuses. The Commission rather gave priority to investigations concerning exclusionary practices (e.g. refusal to deal, predatory pricing), where the dominant firm indirectly harmed final customers by excluding competitors from the market (Gal 2004).

In the Football World Cup Decision (COMP/36.888), the European Commission sanctioned the French football association for abuse of dominance, since it discriminated foreign consumers in the process of buying tickets for the matches of the 1998 World Cup in France. Similarly, the Commission sanctioned Deutsche Post under Art. 102 TFEU for the preferential treatment given the distribution of mails originating in Germany over letters having a foreign origin (COMP/38.745). However, in both decisions the Commission did not openly discuss the issue of the scope of application of Art. 102 TFEU vis-à-vis abuses that harm final consumers.

Similarly, neither the EU Court of Justice nor the General Court have ever clarified whether and to what extent Art. 102 TFEU covers exploitative abuses that harm final consumers. In his opinion in $M E O$, Advocate General (AG) Wahl argued that exploitative forms of price discrimination are "extremely rare" (Case C-525/16, AG's Opinion, para. 80). In fact, while a vertically integrated firm has an incentive to discriminate its customers when the latter are its competitors in the downstream market (e.g. margin squeeze), a non-vertically integrated firm does not have any incentive to discriminate some of its customers, since this strategy would negatively affect its reputation and would not create any benefit for the dominant firm in terms of market share (Case C-525/16, AG's Opinion, para. 79). Therefore, AG Wahl indirectly suggested that Art. 102(c) TFEU should only sanction forms of price discrimination that represent "primary line of injury" (i.e. exclusion of competitors/industrial customer). In line with the AG's opinion, the CJEU recognised in $M E O$ that "...the undertaking in a dominant position, in principle, has no interest in excluding one of its trade partners from the downstream market" (Case C-525/16, para. 
35). However, the Court neither in $M E O$ nor in any other ruling has ever excluded a priori the application of Art. 102(c) TFEU to exploitative forms of price discrimination. Therefore, the question of whether and to what extent Art. 102 TFEU could sanction abuses that directly harm consumers has never been fully clarified in CJEU case law.

According to Akman, Art. 102(c) TFEU relies on the expression "trading partners", rather than "undertakings", unlike the other provisions of the Treaty (Akman 2007, 498). Therefore, consumers could also be considered "trading partners" when they buy goods and services from the dominant firm. Secondly, the reference to "competitive disadvantage" in Art. 102(c) TFEU could cover consumers too-i.e. "discriminated" consumers who have to pay a higher price and thus are placed at a "disadvantage" compared to the consumers who pay a lower price for the same product (Akman 2007, 498). Finally, consumers are also "competing" in the market, to a certain extent, in order to purchase a product (Akman 2007, 499).

To sum up, the European Commission and NCAs have traditionally sanctioned under Art. 102 TFEU exclusionary practices that harm industrial customers-i.e. competitors of the dominant firm. However, Art. 102 TFEU could also sanction exploitative conducts that directly harm final consumers (Townley et al. 2017, 33). The digital economy generates new challenges for the enforcement of EU competition law: personalised pricing and other conducts that were not technologically feasible until a few years ago should lead to a re-consideration of the enforcement of Art. 102 TFEU, extending its scope of application to abuses directly harming final consumers. This shift would simply represent an enforcement choice that would not require any amendment of the Treaty.

\subsection{Art. 102(c) TFEU}

As mentioned in the introduction, a dominant firm breaches Art. 102(c) TFEU when it applies "dissimilar conditions to equivalent transactions with other trading parties, thereby placing them at a competitive disadvantage". Price discrimination clearly falls within the scope of "dissimilar conditions". The discrimination can take different forms: besides classical discrimination in the form of different retail/wholesale prices, the dominant company can discriminate its customers via selective price cuts and target rebates. Art. 102(c) TFEU clarifies that price discrimination is not abusive per se: a dominant company breaches this provision if it differentiates the price of its products/services in relation to "equivalent transactions", and by placing certain customers at a "competitive disadvantage" in comparison to "other trading partners". Finally, as further discussed in the following paragraphs, the CJEU case law has recognised that the dominant company can put forward "objective justifications" to justify its conduct.

The concept of "equivalent transactions" was first interpreted by the CJEU in United Brands (Case 27/76). According to the Court, to determine whether transactions involving the same product were indeed "equivalent", the European Commission should analyse the "differences in transport costs, taxation, customs duties, the wages of the labour force, the conditions of marketing, the differences in the parity 
of currencies, the density of competition..." (Case 27/76, para. 228). On the other hand, the Court pointed out that the different levels of demand for bananas in different EU Member States could not be sufficient to justify a persistent price disparity within the EU common market (Case 27/76, para. 229). United Brands case law has been consistently upheld in the subsequent CJEU jurisprudence: the Court has generally looked at the nature of the product/service sold by the dominant company to its customers and assessed whether the different supply costs faced by the dominant company made the transactions "equivalent". For instance, in British Airways (Case C-95/04 P) the CJEU concluded that the sale of airlines tickets by British Airways to different travel agents in UK represented equivalent transactions. Although the tickets concerned different destinations, the CJEU considered equivalent the type of service provided by British Airways to different travel agents (Case C-95/04 P, para. 136-141).

The concept of "competitive disadvantage" has also been interpreted by CJEU case law. Traditionally, the Court has "presumed" that price discrimination places the customer who pays the higher price for the same product/service at a competitive disadvantage in comparison to the "other trading partners" (i.e. the customer's competitors). In particular, the Court of Justice ruled in British Airways that the European Commission was not required to prove that the price discrimination caused "an actual quantifiable deterioration in the competitive position" of the discriminated customer (Case C-95/04 P, para. 145). Similarly, in Clearstream the General Court did not assess whether the price discrimination had resulted in a loss of market share for the discriminated customers (Case T-301/04, para. 194).

The case law on "competitive disadvantage" has been revised by the CJEU in its recent $M E O$ ruling (Case C-525/16). Similar to British Airways, the Court ruled that Art. 102(c) TFEU does not require the European Commission/the NCA to estimate the competitive disadvantage suffered by the discriminated customer (Case C-525/16, para. 27). On the other hand, in line with the more effect-based approach to Art. 102 TFEU followed by the CJEU after Intel (Case C-413/14 P), in MEO the Court ruled that the competition enforcer should take into consideration "all the relevant circumstances" to determine whether price discrimination could produce a competitive disadvantage (Case C-525/16, para. 28). In particular, by analogy to Intel, the CJEU ruled that the NCA should take the following elements into consideration as relevant factors (Case C-525/16, para. 31):

- The undertaking's dominant position;

- The negotiating power of the customer of the dominant firm as regards the tariffs;

- The conditions and arrangements for charging those tariffs;

- The duration and amount of the tariffs;

- The existence of a strategy by the dominant firm aiming to exclude from the downstream market one of the trading partners "which is at least as efficient as its competitors".

While the conditions mentioned in $M E O$ essentially mirror those ones listed in Intel (Case C-413/14 P, para. 139-140), the standard of legal proof is different 
in the two judgements. In particular, while in Intel the CJEU indicated a list of conditions that the Commission should consider during the administrative procedure to rebut the initial presumption of foreclosure caused by the abuse (Case C-413/14 P, para. 141), the conditions listed by the CJEU in $M E O$ should be relied by a competition enforcer to establish the presence of a competitive advantage, in order to prove the existence of an abuse of dominance (Ritter 2019, 267).

Finally, while the European Commission/the NCA faces the burden of proof concerning the existence of equivalent transactions and the competitive disadvantage suffered by the discriminated customers, the dominant firm can put forward "objective justifications" and argue that the price disparity is legal (Case C-525/16, para. 31). While objective justifications are possible in theory, the Court has rarely accepted them in practice. This is due to the fact that most of the cases sanctioned under Art. 102(c) TFEU concern forms of price discrimination connected to the customers' nationality-i.e. cases that have a close link to the EU internal market integration. In accordance with United Brands case law (Case 27/76, para. 233), the Court of Justice has never accepted objective justifications vis-à-vis forms of price discrimination among customers based in different EU Member States. It remains to be seen whether and to what extent the Court will change its approach to the objective justifications after $M E O$.

In $M E O$, the CJEU extended the effect-based analysis of Art. 102 TFEU to exploitative abuses. In particular, the references to the assessment of the "relevant circumstances" clearly come from the Intel ruling. From this point of view, $M E O$ should be welcome, since it aligns the CJEU case law in relation to the analysis of different categories of abuses under Art. 102 TFEU. On the other hand, the language of the Court in $M E O$ is ambiguous in relation to a number of issues. In particular, after $M E O$ it remains unclear what the required threshold is that a competition agency should satisfy in order prove the presence of a competitive disadvantage: in the ruling, the CJEU referred to behaviours "capable of distorting competition" (Case C-525/16, para. 37). As recently argued by Ritter, the reference to the word "capable" implies a lower threshold in comparison to the "likely" standard used by the Commission in its Guidance Paper on Art. 102 (para. 19), which rather requires the competition agency to prove that the harm is "potential" rather "purely hypothetical" (Ritter 2019, 269). Secondly, in $M E O$ the Court referred to forms of price discrimination that "distort" competition, by thus being cable of causing a competitive disadvantage for the discriminated customer-i.e. once again, a lower threshold is comparison to a reference to a "restriction" of competition, likely to cause a competitive disadvantage (Ritter 2019, 271). In view of these considerations, Ritter has concluded that $M E O$ has introduced a rather "low threshold" concerning the presence of competitive disadvantage, which does not substantially diverge from the previous CJEU case law (Ritter 2019, 273). As mentioned above, in fact, the Court did not introduce a requirement for the competition agency "to quantify" the competitive disadvantage caused by the discriminated customer due to the price discrimination, but only to take into consideration "all the relevant circumstances" in assessing the price discrimination strategy implemented by the dominant firm (Case C-525/16, para. 37). 


\subsection{Challenges faced by a competition agency in assessing personalised pricing after MEO}

In spite of the consideration mentioned in the previous sub-section, it could be argued that $M E O$ has increased the burden of proof that competition enforcers would face in sanctioning forms of personalised pricing under Art. 102(c) TFEU. In particular, in order to assess the presence of a discriminatory strategy, the NCA would need to prove that the price discrimination is a repeated conduct; a strategy systematically implemented by the online platform vis-à-vis certain customers. However, consumers are often not aware of having been the subject of discrimination. Secondly, geographic discrimination could affect consumers based in different countries, outside of the NCA's jurisdiction. Thirdly, the NCA would need to analyse the inner logic of the firm's algorithm to understand whether it systematically discriminates between different categories of consumers. Such an analysis would be a very complex task for the NCA. Fourthly, the dominant online platform could put forward objective justifications. For instance, the platform could argue that the personalised pricing strategy leads to forms of optimal prices that increase the overall consumers' welfare. As argued in Sect. 3, price discrimination has a "mixed" effect on consumers' welfare, and sometimes it can increase the welfare of "poorer" consumers. Therefore, the NCA/the European Commission would need to assess the impact of personalised pricing on the overall consumer welfare of "budget conscious" and "affluent" consumers.

Finally, the challenges mentioned above would also be influenced by the type of product subject to the personalised pricing strategy. In case of a "physical good" (e.g. any tangible object sold on Amazon and delivered to the consumer by mail), the agency could compare the price charged by the online platform for a specific good to different customers during a certain period of time. In spite of the technical challenges mentioned above, the agency could still find evidence of the enforcement of a personalised pricing strategy by, for instance, looking at the sales list of the online marketplace. The agency should pay particular attention to whether or not changes in price are the result of personalised pricing, rather than dynamic pricing (i.e. real-time change in the product supply and demand). By contrast, if the product was either a service (e.g. a car ride booked via Uber) or a piece of information, the product itself might—-depending on the circumstances-be highly "personalised" and fit the consumer requests. In other words, it would be highly difficult, sometimes impossible, for the enforcement agency to identify "equivalent transactions" (i.e. the first limb of the United Brands test) and thus prove an infringement of Art. 102 TFEU.

Another major challenge faced by an NCA/the European Commission in assessing a personalised pricing strategy under Art. 102(c) TFEU would be represented by the identification of the appropriate counterfactual scenario, in order to estimate the harm to the consumers' welfare caused by the price discrimination strategy. According to its Guidance Paper on Article 102, in assessing the impact of an abusive practice on the consumers' welfare, the Commission will

"...compare the actual or likely future situation in the relevant market (with the dominant undertaking's conduct in place) with an appropriate counterfactual, 
such as the simple absence of the conduct in question or with another realistic alternative scenario, having regard to established business practices." (Guidance Paper, para. 21)

The Guidance Paper thus identifies 2 possible counterfactual scenarios: either the ex-ante market situation (i.e. before the beginning of the infringement) or an "alternative" scenario, which is comparable with the relevant market. Authors have broadly debated which standard should be the appropriate one: while some authors have argued that the ex-ante scenario is an "easier" counterfactual to define and thus more manageable to enforce by the authority (e.g. Lopatka and Page 2001), others have argued in favor of "alternative" scenarios, which however have to be comparable to the relevant market (Hellström et al. 2009, Hjelmeng 2013). The Guidance Paper, however, seems to accept both types of counter-factual scenarios as appropriate, rather suggesting a case-by-case approach. In addition, the Court of Justice has never taken a clear position in its case law in relation to this issue.

In the context of a consumers' welfare analysis of a personalised pricing strategy implemented by a dominant online platform, the ex-ante scenario would be the appropriate counter-factual if the competition agency could clearly identify the moment when the price discrimination strategy started and if the latter concerned the same groups of consumers. In other words, by looking at the prices charged by the online platform before and after the implementation of the personalised pricing strategy, the agency could assess the impact of the price discrimination strategy on the welfare of different groups of consumers. Alternatively, if the ex-ante market scenario could not be clearly identified, the competition authority could look at the price charged for similar products/services by other platforms operating in neighboring markets (i.e. similar, though not identical, geographic and product markets). However, this type of analysis would certainly be more speculative, and thus more complex for the agency to administer. In particular, the burden of proof of identifying an "appropriate alternative" scenario would be quite high, and the NCA/European Commission would run the risk to lose the case on appeal.

As argued in Sect. 3, personalised pricing has an ambiguous impact on consumers' welfare, which requires a case-by-case analysis. In spite of the caseby-case approach that characterizes competition policy, an NCA/the European Commission would face a number of challenges in sanctioning a personalised pricing strategy by a dominant online platform under Art. 102(c) TFEU. First of all, the proof of a competitive disadvantage under the recent $M E O$ case law would be a major challenge for any NCA committed to investigating a case of personalised pricing under Art. 102(c) TFEU. Secondly, the agency should identify an appropriate counter-factual scenario in order to measure the impact of a personalised pricing strategy on the consumers' welfare. In view of these considerations, it is not surprising that no NCA has ever investigated any case of behavioural discrimination in data markets. It seems unlikely that any enforcement agency will make any attempt to this regard in the near future. 


\section{Competition law remedies to personalised pricing}

\subsection{Behavioural remedies vis-à-vis personalised pricing}

As mentioned in the previous section, $M E O$ has increased the burden of proof that a competition enforcer would face in sanctioning a case of personalised pricing under Art. 102(c) TFEU. Nevertheless, if an antitrust agency found enough convincing evidence to sanction a dominant online platform, the issue of defining suitable remedies would come up.

A fine coupled with a cease-and-desist order would probably be an unwise solution, due to the lack of precedents in this area. Due to the new challenges posed by competition law enforcement in the digital economy, NCAs should "guide" the firms' behaviour, rather than sanction it. The European Commission can conclude commitments with the undertakings subject to a competition law investigation under Art. 101-102 TFEU (Art. 9 Reg. 1/2003). With the entry into force of the new ECN + Directive, all NCAs will have the power to adopt commitment decisions (Art. 12 Dir. 2019/1).

Commitments are, generally speaking, divided into "structural" and "behavioural" remedies (Dunne 2014). The first category includes commitments that aim at solving the anti-competitive behaviour via a "divestiture" of the firm's assets (e.g. shares in another firm, business units, patents), whereby the firm's market power within the relevant market is reduced. On the other hand, behavioural commitments are an open category of remedies that can be jointly designed by the firm and the NCA. Via a behavioural remedy, a firm commits to behave in a certain manner in the future in order to "prevent" a competition law violation (e.g. the firm might agree to continue to supply to a competitor for a certain period). Behavioural commitments work ex-ante, and thus they are situated at the borderline with market regulation. As recognised by a 2016 House of Lords report, the length of commitment negotiations is a possible obstacle to the enforcement of this type of antitrust remedy in the context of the digital economy (UK House of Lords 2016, para. 188). Besides the reluctance of competitors to "green light" the proposed commitments, the length of the negotiations may also be caused by the technical complexity of the remedies proposed (UK House of Lords 2016, para. 191). On the other hand, the report also recognised that commitments are flexible in terms of design (UK House of Lords 2016, para. 187). In particular, since they are tailor-made, commitments better fit the peculiarities of the data economy than prescriptive regulation. While structural commitments are generally excluded in the context of the data economy, since they would negatively affect the consumers' welfare, behavioural commitments might serve as a possible alternative to fines and cease-and-desist orders. This alternative route would allow the competition agency to guide the industry players and to fill in the gaps found in the regulatory framework.

By working in cooperation with the dominant online platform, the NCA could design a number of behavioural commitments aiming at solving the competitive issues caused by personalised pricing. In particular, we argue that four types of remedies could be designed: 
- Limiting the number of personal data collected by the platform: Online platforms can discriminate their customers due to the large number of personal data they collect. Even access to anonymised data might be sufficient to implement a discriminatory strategy: via data fusion, the platform can infer the reservation price of "small" group of customers and use this information to discriminate its customers. In order to prevent a strategy of personalised pricing that harms the majority of final consumers, an NCA/the European Commission could impose a number of limitations on the types of data gathered by the dominant platform.

- Sharing the customers' data with competing platforms: Instead of asking the platform to reduce the amount of data collected and thus hampering possible efficiencies generated by data analytics, the behavioural remedy could require the online platform to "share" a number of customers' data with competing platforms. A similar type of remedy has already been applied by the European Commission in the airline industry: a number of concentrations have been cleared by the European Commission subject to the condition that the merging parties open their frequent flyer programs to competing airlines (Case COMP/39.596; Case COMP/AT.39595; Case COMP/AT.39964). As a consequence of this merger remedy, travellers can redeem and acquire miles by traveling with competing airlines. This remedy encourages flyers to switch to other operators, and thus fosters competition between the merging parties and competing airlines. However, by making compatible the frequent flyer programs of the merging parties and their competitors, the European Commission de facto required the merging parties to share important data about their frequent flyers (i.e. the premium customers) with competitors. The latter were thus able to target the frequent flyers with ad hoc offers. This type of remedy could also be taken into consideration in digital markets, by requiring the dominant online platform to share some information about its customers with its competitors. As a result, competitors would be able to target the customers of the dominant firm with ad hoc offers, and consumers would be encouraged to switch suppliers.

- Transparency requirement: As argued in Sect. 3.2, behavioural economics show that consumers are not against personalised pricing per se. They rather dislike the lack of transparency of the price setting mechanisms followed by algorithms. In order to solve this problem, a possible behavioural remedy could introduce transparency requirements by the online platform when implementing a personalised pricing strategy. In other words, the platform should commit to disclose to its users whether it is implementing a strategy of personalised pricing and what the parameters taken into consideration to enforce this strategy are.

- Opt-out right: As a further tool to empower consumers to make an informed choice when shopping online, the platform could be required to grant an opt-out right to its users. Consumers would thus not only have the right to be informed when they are subject to a form of price discrimination, but they could also have the right to be subject to uniform pricing, if they wish. This measure could lead to different choices by the platform users: while some customers would likely opt for the safeguard provided by the uniform price, "strategic" users could take the risk of being discriminated, perhaps benefiting from a cheaper price than the uniform price. The opt-out right would be more regulatory in its character than the 
transparency obligation. It would be suitable in the rare cases of digital monopolies, where the users would not have the opportunity to switch to another supplier.

These four behavioural remedies represent possible alternatives that would be applicable only if the NCA/the European Commission were able to prove that the personalised pricing strategy implemented by the dominant online platform had an overall negative impact on the consumers' welfare. These remedies imply different degrees of intervention into the market dynamics: while the transparency obligation represents the "lightest" remedy, the limitation/sharing of the customers' data and the opt-out right would strongly affect the platform's business model. As a consequence, the NCA/the European Commission should be careful in opting for these solutions, which should be designed in cooperation with the platform.

The four remedies discussed above would pose a number of challenges for the NCA/the European Commission. First of all, the competition enforcer would have to monitor the correct implementation of the remedies by the platform over a number of years, resulting in significant costs. In addition, the design of these remedies would also cause a number of challenges. For instance, by limiting the amount of personal data collected by the online platform, the competition agency might run the risk of reducing the quality of the products sold by the online platform, thereby negatively affecting the consumers' welfare.

The data sharing remedy would also cause a number of challenges for the enforcement agency. First of all, it would be hard for the competition authority to define from the outset which data would be subject to the duty to share (Colangelo and Maggiolino 2017, 274). The ability to extract useful information via data analytics is primarily determined by the algorithm, rather than by the amount of cumulated data. Therefore, data sharing might not be sufficient to rebalance the competitive disadvantage suffered by the competitor of the dominant firm if the latter does not have access to the technology/algorithms to process the data shared. Secondly, data may have a limited lifespan, depending on the context. Thus, a sharing obligation might prove to be useless for the competitor of the dominant firm after a certain amount of time has passed (Colangelo and Maggiolino 2017, 275). Thirdly, it would be hard for the NCA to define the price for the sharing of data (Colangelo and Maggiolino 2017, 275). The value of a dataset is rather subjective, and it is strongly influenced by the possible outcomes of data analytics. Fourthly, in the lack of the consumers' consent to share their data, a sharing obligation might create a conflict with data protection rules (Kathuria and Globocnik 2019). Finally, a sharing obligation, usually imposed by the authority to remedy an exclusionary practice by the dominant firm (e.g. refusal to deal), might not necessarily benefit consumers in the context of an exploitative abuse such as personalised pricing: the competitors might not be as efficient as the dominant platform, and thus unable to provide better and cheaper products to consumers even if the platform shares its customers' data.

The transparency and the opt-out obligations, though "weaker" forms of remedies, would also pose a number of challenges as regards their design. First of all, a transparency obligation might overlap with existing consumer and data protection rules (cf., for instance, Art. 13-15 GDPR) and thus it might not necessarily represent 
an added value in comparison to the existing legal framework. Secondly, an opt-out right might directly interfere with the business model of the online platform and not necessarily benefit consumers.

In view of these considerations, the NCA/European Commission would need to carry out a careful case-by-case analysis before adopting any of the remedies suggested above. The challenges in the design of suitable remedies show the need for the competition authority to conclude commitment agreements with the parties, rather than unilaterally imposing a behavioural remedy. By making use of commitments, remedies can be designed to match the needs of both the dominant firm and its users. Secondly, a review clause should be included in the behavioural decision in order to adjust the remedy to changing market conditions (Bary and De Bure 2017).

\subsection{Antitrust remedies v. omnibus legislation-some considerations}

The behavioural remedies discussed in the previous section open the discussion on the overlap between competition law and sector-regulation. In particular, while the remedies concerning the limitation/sharing of the customers' data get inspiration from data protection law, the transparency requirement and the opt-out right derive from the EU consumer law acquis.

Although a deep analysis of EU data protection and consumer law acquis would go beyond the scope of this article, it is worth mentioning that EU competition, data protection and consumer law share a number of "family ties". These ties are particularly strong in the context of the data economy (Costa-Cabral and Lynskey 2017; Graef 2018). Although these policies share the common aim of safeguarding the welfare of individuals in the market economy, they have different objectives, scope of application and enforcement regimes. In Asnef-Equifax, the CJEU recognised that EU competition law should not pursue data protection goals (Case C-238/05, para. 63). However, in Astra Zeneca the Court pointed out that the "illegality of abusive conduct under [now: Art. 102 TFEU] is unrelated to its compliance or non-compliance with other legal rules and, in the majority of cases, abuses of dominant positions consist of behaviour which is otherwise lawful under branches of law other than competition law" (Case C-457/10, para. 132). In view of Astra Zeneca case law, competition law enforcers should have the discretion to intervene in cases of market failures in the data economy, even in the presence of overlapping data protection and consumer law.

Although the enforcement of competition law in digital markets should not be limited by existing sector regulation, the NCA could dialogue with the relevant regulators (i.e. data protection/consumer protection authorities) in designing the behavioural remedies discussed in the previous section. By exchanging information, organising joint sector inquiries/investigations and discussing the design of possible remedies, the NCA could coordinate its enforcement actions with sector regulators. Such cooperation is already well-established between NCAs and regulators of network industries (e.g. energy and telecom). Following the new challenges generated by the digital economy, such kind of cooperation should also be extended to data and consumer protection authorities (EDPS 2016). 
The intervention of a competition authority in the digital economy would be particularly suitable to fill the "gaps" in the relevant regulatory framework. To this regard, it is worth noticing that the GDPR has generally enhanced and uniformed the degree of data protection in Europe. However, being an omnibus legislation applicable in a variety of entirely different situations, the GDPR contains some rather open provisions. In particular, the GDPR strongly relies on the concept of "consent" by the data subject to authorise the process of his/her personal data (Art. 6.a GDPR). Due to the lack of transparency of the data protection terms, however, Internet users are often unable to fully exercise an informed consent (Kerber 2016, 642). Secondly, the GDPR is not applicable to non-personal data-i.e. anonymised data as well as those data that are anonymous from the outset, such as weather data (Art. 2.1 GDPR; Recital 26 GDPR). Nevertheless, via data fusion, online platforms may create user profiles even on the basis of anonymised data (Ohm 2010, 1711), thus circumventing the scope of application of the GDPR. In view of these considerations, a competition policy intervention could "fill the gaps" in the data regulatory framework. In particular, behavioural remedies concerning the limitation/sharing of the customers' data could fill the gaps in the GDPR and prevent personalised pricing when the latter hampers the consumers' welfare.

Similar considerations would be applicable to the EU consumer acquis. Annex 1 of the Unfair Commercial Practices Directive prohibits a number of contractual clauses "which are in all circumstances considered unfair" (Annex 1 Dir. 2005/29/ EC). Coming back to possible forms of personalised pricing discussed in Sect. 2, it is clear that "fake" special offers would fall within the scope of the black list of clauses contained in the Directive. Annex 1, in fact, considers as misleading commercial practice "falsely stating that a product will only be available for a very limited time..." (Para. 7, Annex 1 Dir. 2005/29/EC). By contrast, "steering" and the other forms of price discrimination discussed in Sect. 2 would not be considered per se "unfair" commercial practices. The current EU consumer acquis has thus a number of "gaps" which could be filled in via ad hoc antitrust intervention. From this point of view, the transparency requirements and the opt-out rights discussed in the previous sections would represent suitable remedies to empower consumers to make an informed choice in cases of personalised pricing.

Besides filling the "gaps" in the regulatory framework, competition law intervention would be suitable in digital markets due to its case-by-case approach. As discussed in Sect. 3, due to its ambiguous effects on consumers' welfare, there is no reason to prohibit every form of personalised pricing. Unlike omnibus regulation, competition law would only sanction cases of personalised pricing that negatively affect the consumers' welfare.

\section{Conclusions}

Big data and algorithms favour personalised pricing in digital markets. In particular, via big data analytics, nowadays it is easier for online platforms to guess the reservation price of ever "smaller" groups of consumers. A tendency towards the identification of individual preferences is expected in the coming years (OECD 
$2018,5)$. In other words, although perfect price discrimination might still not be possible in most situations, we are getting closer to such a scenario. Recent technological innovations thus challenge the traditional assumption that first-degree price discrimination (i.e. individual pricing) is de facto impossible. Although different forms of price discrimination in digital markets are already technologically feasible, there is limited evidence that online platforms are already enforcing this kind of discriminatory strategy. This might be due to the fact that online retailers are worried that the implementation of personalised pricing might harm their reputation.

In this paper, we have discussed the possible application of Art. 102(c) TFEU to sanction forms of personalised pricing by dominant online platforms. In particular, we have looked at the exploitative, rather than the exclusionary dimension of price discrimination under Art. 102(c) TFEU. Although no competition authority has sanctioned a case of personalised pricing under Art. 102 TFEU (yet), the expected rise of these business practices in the coming years will generate a number of questions concerning the enforcement of EU competition law in this area; questions that we have tried to address in this paper. In particular, we have focused our attention on the impact of personalised pricing on consumers' welfare, the NCA/European Commission enforcement challenges, and possible antitrust remedies.

The review of the recent economics literature on price discrimination has shown that personalised pricing has an ambiguous effect on consumers' welfare. In particular, price discrimination generally increases product affordability, allowing "poorer" consumers to pay a "lower" price for the product in comparison to "richer" consumers. However, via profiling, the platform could adjust the sale price of the product closer to the reservation price of every consumer, shifting part of the consumer welfare to the firm. In an imperfect competitive scenario, the impact of personalised pricing on consumers' welfare would be influenced by a number of variables, such as the consumers' brand preferences and search costs, as well as the information to which the competing platforms have access. In view of this ambiguity, personalised pricing should not be prohibited per se; it would require a case-by-case analysis of its impact on the overall consumers' welfare. Finally, new studies in the area of behavioural economics show that consumers do not accept the "secrecy" of personalised pricing, since the parameters followed by the algorithms to set the price are unknown. In view of the consumers' resistance vis-à-vis personalised pricing, firms might thus avoid implementing such strategy in order to safeguard their reputation. Behavioural economics might thus explain the limited evidence which has so far emerged concerning the implementation of personalised pricing strategies by online platforms.

Even if an NCA/the European Commission found that personalised pricing by a dominant online platform negatively affected consumers' welfare, the agency would face a number of challenges to prove the case under Art. 102(c) TFEU. First of all, it remains unclear whether and to what extent Art. 102 TFEU could sanction cases of price discrimination harming final consumers, rather than industrial customers. Since the digital economy introduces new business practices that directly harm final consumers, in this paper we have argued in favour of "broadening" the scope of application of 
Art. 102 TFEU. However, the question concerning the scope of application of Art. 102 TFEU remains open, since it has never been clarified by CJEU case law.

In addition, in view of the recent CJEU ruling in $M E O$, the competition enforcer would face a high burden of proof to sanction a case of personalised pricing under Art. 102(c) TFEU. First of all, the authority would have to prove that the personalised pricing by the dominant online platform is a repeated conduct, and that the platform implemented an overall strategy to discriminate different groups of consumers. The collection of such evidence would be particularly burdensome for the competition agency. Secondly, the online platform could put forward a number of objective justifications for the personalised pricing strategy (e.g. the discriminatory pricing maximised the welfare of most users). Finally, the agency would need to identify an appropriate counterfactual scenario in order to assess the impact of the personalised pricing strategy on the consumers' welfare.

Although it is unlikely that an NCA/the European Commission will sanction any case of personalised pricing in the near future, if an enforcement authority was sufficiently "brave" to explore this road, the issue of suitable antitrust remedies would be on the table. In this paper, we have argued in favour of behavioural commitments negotiated between the dominant online platform and the enforcement authority. Behavioural commitments would be more flexible than a fine coupled with a cease-and-desist order, and thus they could adjust to the needs of the dominant platform. In particular, we have argued that the NCA/the European Commission could take recourse to the principles given in the GDPR to design behavioural remedies. In particular, the introduction of limits on the amount of personal data collected by the platform or the obligation to share data with competitors should be considered suitable remedies that would reduce the negative effects of personalised pricing. Alternatively, in line with the EU consumer acquis, the NCA/the European Commission could opt for transparency requirements and/or opt-out rights as suitable behavioural remedies.

In view of the overlap with data protection and consumer law, we have argued that the NCA/the European Commission should actively cooperate with the competent data protection and consumer protection authorities when designing these remedies. In particular, the antitrust remedies could fill the gaps in the relevant regulatory framework. Finally, due to their case-by-case approach, antitrust remedies seem more suited to the fast dynamics of the digital economy than does an omnibus legislation.

This paper is a first attempt to analyse personalised pricing under Art. 102 TFEU. In spite of all the limitations discussed in this paper, EU competition law policy certainly has a role to play in this field in the near future. Online platforms will continue facing the Hamletic debate on the legality of personalised pricing; they are waiting for further guidance from courts and competition law enforcers on the legality of this business practice under EU competition law.

Acknowledgements Open access funding provided by Max Planck Society.

Open Access This article is distributed under the terms of the Creative Commons Attribution 4.0 International License (http://creativecommons.org/licenses/by/4.0/), which permits unrestricted use, distribution, and reproduction in any medium, provided you give appropriate credit to the original author(s) and the source, provide a link to the Creative Commons license, and indicate if changes were made. 


\section{References}

Acquisti, A., \& Varian, H. (2005). Conditioning prices on purchase history. Marketing Science, 24(3), 367-381.

Akman, P. (2007). To abuse, or not to abuse: Discrimination between consumers. European Law Review, 32(4), 492-512.

Akman, P. (2009). Searching for the long-lost soul of article 82 EC. Oxford Journal of Legal Studies, 29(2), 267-303.

Armstrong, M. (2006). Recent developments in the economics of price discrimination. In R. Blundell, W. Newey, \& T. Persson (Eds.), Advances in economics and econometrics: Theory and applications (pp. 1-46). Cambridge: Cambridge University Press.

Bary, L., \& De Bure, F. (2017). Disruptive innovation and merger remedies: How to predict the unpredictable? Concurrences, 3, 1-9.

Belleflamme, P., \& Vergote, W. (2016). Monopoly price discrimination and privacy: The hidden cost of hiding. Economics Letters, 149, 141-144.

Bergemann, D., Brooks, B., \& Morris, S. (2015). The limits of price discrimination. American Economic Review, 105(3), 921-957.

Bourreau, M., De Streel, A., Graef, I. (2017). Big data and competition policy: Market power, personalised pricing and advertising. Cerre Project Report. Retrieved July 12, 2019 from https://cerre.eu/ publications/big-data-and-competition-policy.

Cabral, L. (2016). Dynamic pricing in customer markets with switching costs. Review of Economic Dynamics, 20, 43-62.

Carlton, D., \& Perloff, J. (1999). Modern industrial organization. Reading, MA: Addison-Wesley.

Case 27/6. (1976). United Brands Company v. Commission. ECLI:EU:C:1978:22.

Case C-413/14 P. (2017). Intel Corp. V. European Commission. ECLI:EU:C:2017:632.

Case C-525/16. (2018). MEO-Serviços de Comunicações e Multimédia SA v. Autoridade da Concorrência. ECLI:EU:C:2018:270.

Case C-95/04 P. (2007). British Airways v. European Commission. ECLI:EU:C:2007:166.

Case T-301/04. (2009). Clearstream Banking AG and Clearstream International SA v. European Commission. ECLI:EU:T:2009:317.

Colangelo, G., \& Maggiolino, M. (2017). Big data as misleading facilities. European Competition Journal, 13(2-3), 249-281.

Consolidated version of the Treaty on the Functioning of the European Union. (2012). OJ C-326, pp. 47-390.

Costa-Cabral, F., \& Lynskey, O. (2017). Family ties: The intersection between data protection and competition in EU law. Common Market Law Review, 54(1), 11-50.

Directive 2005/29/EC of the European Parliament and of the Council of 11 May 2005 concerning unfair business-to-consumer commercial practices in the internal market and amending Council Directive 84/450/EEC, Directives 97/7/EC, 98/27/EC and 2002/65/EC of the European Parliament and of the Council and Regulation (EC) No 2006/2004 of the European Parliament and of the Council. OJ L-149/22, 11.6.2005.

Directive (EU) 2019/1 of the European Parliament and of the Council of 11 December 2018 to empower the competition authorities of the Member States to be more effective enforcers and to ensure the proper functioning of the internal market. OJ L-11/3, 14.1.2019.

Dunne, N. (2014). Commitment decisions in EU competition law. Journal of Competition Law and Economics, 10(2), 399-444.

Esteves, R.-B., \& Reggiani, C. (2014). Elasticity of demand and behaviour-based price discrimination. International Journal of Industrial Organization, 32, 46-56.

European Commission Communication. (2009). Guidance on the Commission's enforcement priorities in applying Article 82 of the EC Treaty to abusive exclusionary conduct by dominant undertakings, OJC $45 / 7$.

European Commission decision of 20.7.1999. Case COMP/36.888, 1998 Football World Cup.

European Commission decision of 20.10.2004. Case COMP/37.745, BdKEP-Restrictions on Mail Preparation.

European Commission decision of 14.10.2010. Case COMP/39.596, BA/AA/IB.

European Commission decision of 23.5.2013. Case COMP/AT.39595, Continental/United/Lufthansa/Air Canada. 
European Commission decision of 12.5.2015. Case COMP/AT.39964, Air France/KLM/Alitalia/Delta.

European Data Protection Supervisor (EDPS). (2016). EDPS opinion on coherent enforcement of fundamental rights in the age of big data. Opinion 8/2016, published on 23.3.2016. Retrieved July 12, 2019 from https://edps.europa.eu/sites/edp/files/publication/16-09-23_bigdata_opinion_en.pdf.

Ezrachi, A. (2017). Sponge. Journal of Antitrust Enforcement, 5(1), 49-75.

Ezrachi, A., \& Stucke, M. (2016). Virtual competition. Cambridge, MA: Harvard University Press.

Filistrucchi, L., Geradin, D., \& Van Damme, E. (2013). identifying two-sided markets. World Competition, 36(1), 33-59.

Gal, M. S. (2004). Monopoly pricing as an antitrust offense in the US and the EC: Two systems of belief about monopoly? Antitrust Bulletin, 49, 343-384.

Geradin, D., \& Petit, N. (2006). Price discrimination under EC competition law: Another antitrust doctrine in search of limiting principles? Journal of Competition Law and Economics, 2(3), 479-531.

Graef, I. (2015). Market definition and market power in data: The case of online platforms. World Competition, 38(4), 473-506.

Graef, I. (2018). Algorithms and fairness: What role for competition law in targeting price discrimination towards end consumers. Columbia Journal of European Law, 24(3), 541-559.

Hannak A. (2014). Measuring price discrimination and steering on E-commerce Web Sites. In Proceedings of the 2014 conference on internet measurement conference (pp. 305-318). Retrieved July 12, 2019 from https://dl.acm.org/citation.cfm?id=2663744.

Hellström, P., Maier-Rigaud, F., \& Bulst, F. W. (2009). Remedies in European antitrust law. Antitrust Law Journal, 76(1), 43-63.

Hjelmeng, E. (2013). Competition law remedies: Striving for coherence or finding new ways? Common Market Law Review, 50(4), 1007-1038.

Kalimo, H., \& Majcher, K. (2017). The concept of fairness: Linking EU competition and data protection law in the digital marketplace. European Law Review, 42, 210-233.

Kathuria, V., Globocnik, J. (2019). Exclusionary conduct in data-driven markets: Limitations of data sharing remedy. Max Planck Institute for Innovation \& Competition Research Paper No. 19-04. Retrieved July 12, 2019 from https://papers.ssrn.com/sol3/papers.cfm?abstract_id=3337524.

Kerber, W. (2016). Digital markets, data and privacy: Competition law, consumer law and data protection. Gewerblicher Rechtsschutz und Urheberrecht Internationaler Teil (GRUR Int.), 65(7), 639-647.

Leibbrandt, A. (2016). Behavioral constraints on pricing: Experimental evidence on price discrimination and customer antagonism. CESifo Working Paper N. 6214. Retrieved July 12, 2019 from https:// papers.ssrn.com/sol3/papers.cfm?abstract_id=2897489.

Levine, M. E. (2002). Price discrimination without market power. Yale Journal on Regulation, 19(1), $1-36$.

Lianos, I., \& Motchenkova, E. (2013). Market dominance and search quality in the search engine market. Journal of Competition Law and Economics, 9(2), 419-455.

Liu, Q., \& Serfes, K. (2004). Quality of information and oligopolistic price discrimination. Journal of Economics \& Management Strategy, 13(4), 671-702.

Lopatka, J. E., \& Page, W. H. (2001). Devising a microsoft remedy that serves consumers. George Mason Law Review, 9(3), 691-726.

Maggiolino, M. (2017). Personalized prices in European competition law. Bocconi Legal Studies Research Paper No. 2984840. Retrieved July 12, 2019 from https://papers.ssrn.com/sol3/paper s.cfm?abstract_id=2984840.

Malc, D., Mumel, D., \& Pisnik, A. (2016). Exploring price fairness perceptions and their influence on consumer behavior. Journal of Business Research, 69(9), 3693-3697.

Mikians, J., et al. (2012). Detecting price and search discrimination on the internet. In Proceedings of the 11th ACM workshop on hot topics in networks (pp. 79-84). Retrieved July 12, 2019 from https ://www.researchgate.net/publication/232321801_Detecting_price_and_search_discrimination_on_ the_Internet.

Miller, A. (2014). What do we worry about when we worry about price discrimination? The law and ethics of using personal information for pricing. Journal of Technology Law and Policy, 19(41), 43-104.

OECD Secretariat. (2015). Data-driven innovation. big data for growth and well-being. Report published on 6.10.2015. Retrieved July 12, 2019 from http://www.oecd.org/sti/data-driven-innovation-97892 64229358-en.htm. 
OECD Secretariat. (2018). Personalised pricing in the digital era. Report published on 28.11.2018. Retrieved July 12, 2019 from http://www.oecd.org/daf/competition/personalised-pricing-in-the-digit al-era.htm.

Ohm, P. (2010). Broken promises of privacy: Responding to the surprising failure of anonymization. UCLA Law Review, 57(6), 1701-1777.

Pigou, A. C. (1920). The economics of welfare. London: Macmillan.

Regulation (EC) No 1/2003 of the Council of 16 December 2002 on the implementation of the rules on competition laid down in Articles 81 and 82 of the Treaty. OJ L-1/1, 4.1.2003.

Regulation (EU) 2016/679 of the European Parliament and of the Council of 27 April 2016 on the protection of natural persons with regard to the processing of personal data and on the free movement of such data and repealing Directive 95/46/EC. OJ L-119/1, 4.5.2016.

Rhee, K.-E. (2014). What types of switching costs to create under behavior-based price discrimination? International Journal of Industrial Organization, 37, 209-221.

Richards, T. J., Liaukonyte, J., \& Streletskaya, N. A. (2016). Personalized pricing and price fairness. International Journal of Industrial Organization, 44, 138-153.

Ritter, C. (2019). Price discrimination as an abuse of a dominant position under article 102 TFEU: MEO. Common Market Law Review, 56, 259-274.

Rochet, J.-C., \& Tirole, J. (2006). Two-sided markets: A progress report. The Rand Journal of Economics, 37(3), 645-667.

Rubinfeld, D. L., \& Gal, M. S. (2017). Access barriers to big data. Arizona Law Review, 59, 339-381.

Schepp, N.-P., \& Wambach, A. (2016). On big data and its relevance for market power assessment. Journal of European Competition Law and Practice, 7(2), 120-124.

Shiller, B. R. (2014). First degree price discrimination using big data. Working paper of the Economics Department of Brandeis University. Retrieved July 12, 2019 from https://www.brandeis.edu/econo $\mathrm{mics} / \mathrm{RePEc} / \mathrm{brd} / \mathrm{doc} /$ Brandeis_WP58R2.pdf.

Townley, C., Morrison, E., \& Yeung, K. (2017). Big data and personalised price discrimination in EU Competition Law. King's College Law School Research Paper No. 2017-38. Retrieved July 12, 2019 from https://www.kcl.ac.uk/law/research/paper-series.aspx.

UK House of Lords. (2016). Select Committee on European Union, Online Platforms and the Digital Single Market. 10th Report of Session 2015-16. Retrieved July 12, 2019 from https://publications.parli ament.uk/pa/ld201516/ldselect/ldeucom/129/129.pdf.

Varian, H. R. (1989). Price discrimination. In R. Schmalensee \& R. D. Willig (Eds.), Handbook of industrial organization (pp. 597-654). Amsterdam: Elsevier Science Publisher.

White House. (2015). Big data and differential pricing. Report published in February 2015. Retrieved November 6, 2019 from https://obamawhitehouse.archives.gov/sites/default/files/whitehouse_files/ docs/Big_Data_Report_Nonembargo_v2.pdf.

Publisher's Note Springer Nature remains neutral with regard to jurisdictional claims in published maps and institutional affiliations. 